\title{
Subcellular Distribution of Calcium- and Calmodulin-dependent Myosin Light Chain Phosphorylating Activity in Rat Cerebral Cortex ${ }^{1}$
}

\author{
ARTHUR M. EDELMAN, ${ }^{; 2}$ DALE D. HUNTER, ANITA E. HENDRICKSON,§ AND EDWIN G. KREBS* \\ *Howard Hughes Medical Institute Laboratories, $\ddagger$ Department of Pharmacology, and §Departments of Biological Structure and \\ Ophthalmology, University of Washington, Seattle, Washington 98195
}

\begin{abstract}
The subcellular distribution of $\mathrm{Ca}^{2+}$ - and calmodulin-dependent myosin light chain phosphorylating activity in rat cerebral cortex was studied. The activity showed a high degree of association to nerve endings (either crude or purified by discontinuous sucrose density gradient centrifugation). After osmotic shock of the nerve endings, the activity was largely membrane associated and could not be released from membranes by freeze-thawing, dilution, $75 \mathrm{~mm} \mathrm{NaCl}$ or 4 mм EDTA.
\end{abstract}

The association of $\mathrm{Ca}^{2+} /$ calmodulin-dependent myosin light chain phosphorylating activity with synaptosomal membranes suggests a role for calcium-dependent myosin phosphorylation in events relating to neurotransmission.

The contractile proteins myosin and actin have been known for many years to be present in neural tissue in a variety of species (see Trifaro, 1978, for review). Berl et al. (1973) hypothesized that calcium depcndent neurotransmitter release involves actin-myosin interaction in a fashion analogous to calcium-dependent excitationcontraction coupling in muscle. More recently, the involvement of actomyosin in other neuronal functions, such as axonal growth (Letourneau, 1981), axoplasmic transport (Lasek and Hoffman, 1976), and modulation of postsynaptic surface morphology (Cotman and Kelly, 1980), has been suggested. The localization of these proteins supports the possibility of their involvement in such neuronal events. Actin and myosin have been identified in isolated nerve endings (synaptosomes) by enzymatic and immunochemical techniques (Puszkin et al., 1972; Blitz and Fine, 1974; Drenckhahn and Kaiser, 1983) and are found in the areas of synaptic contact of neurons (Toh et al., 1976, Beach et al., 1981; Matus et al., 1982; Drenckhahn and Kaiser, 1983).

The calcium dependence of actin-myosin interaction in tissues is thought to be mediated either by the troponin system (skeletal and cardiac muscle model) or by calmodulin-dependent myosin light chain phosphorylation (smooth muscle and non-muscle tissue model) (Adelstein, 1983). Actin-myosin interaction in neural tissue

Received August 7, 1984; Reviscd February 11, 1985;

Accepted March 8, 1985

We wish to thank Dr. Howard Schulman and R. Scott Hansen for many helpful discussions and R. Scott Hansen for providing the calmodulin used in these studies. We also gratefully acknowledge Dr. Mary Kennedy for providing synapsin I, Floyd Kennedy and Barbara Flug for assistance in preparation of myosin light chains, Criss Meligro for electron microscopic sample preparation, and Evelyn Mercier and Marion Turner for expert secretarial assistance. This work was supported in part by Grants EY 01208, EY 04536, and EY 01730 from the National Eye Institute.

${ }^{2}$ To whom correspondence should be addressed. would therefore be expected to be regulated by the latter mechanism. This conclusion is borne out by recent studies showing that troponin exists (if at all) in negligible quantities in brain (Anthony el al., 1984) and that light chain phosphorylation is required for actin activation of brain myosin ATPase activity (Barylko and Sobieszek, 1983). Although in the latter study, smooth muscle myosin light chain kinase was used as the phosphorylating enzyme, brain also contains enzymes capable of phosphorylating myosin in a calciumand calmodulin-dependent fashion. Dabrowska and Hartshorne (1978) and Hathaway et al., (1981) have identified in brain a 105,000to 130,000 -dalton kinase analogous or identical to smooth muscle myosin light chain kinase, although it remains to be established whether this enzyme is present in neurons as opposed to being associated with CNS vasculature or glial cells. A second enzyme capable of phosphorylating isolated smooth muscle myosin light chains in a calcium- and calmodulin-dependent fashion has been purified from rat brain by a number of investigators (Fukunaga et al., 1982; Bennett et al., 1983; Goldenring ct al., 1983; Yamauchi and Fujisawa, 1983; Kuret and Schulman, 1984). This enzyme (referred to here as brain calmodulin-dependent kinase) is present in high concentrations in mammalian brain. It has a somewhat broader substrate specificity and is larger $(\sim 600,000$ daltons in its holoenzyme form) than myosin light chain kinase. We have recently found that brain calmodulin-dependent protein kinase is capable of phosphorylating whole myosin (smooth muscle) and thereby activating its actin-dependent $\mathrm{Mg}^{2+}$ ATPase activity (Edelman, A. M., M. B. Kennedy, and E. G. Krebs, manuscript in preparation).

The presence in brain of enzymes potentially capable of controlling, via phosphorylation, actin-myosin interaction as well as the synaptic localization of actomyosin prompted us to examine the intracellular distribution of calcium- and calmodulin-dependent myosin light chain phosphorylating activity in cerebral cortex. We report here that this activity is highly concentrated in synaptosomes and within the nerve ending, largely membrane associated. This localization is consistent with a role for this activity in synaptic functioning. Aspects of this work were previously presented in abstract form (Edelman et al., 1984)

\section{Materials and Methods}

Subcellular fractionation. Methods were adapted from those of Whittaker and Barker (1972) and DeRobertis et al. $(1962,1966)$. All procedures were at 0 to $4^{\circ} \mathrm{C}$. Sucrose solutions were prepared using density gradient grade sucrose (Beckman) buffered to $\mathrm{pH} 7.4$ with $5 \mathrm{~mm}$ HEPES. The scheme for subcellular fractionation is shown in Figure 1.

Electron microscopy. Each of the density gradient fractions $A, B$, and $D$ $(0.8 \mathrm{ml})$ and $0.4 \mathrm{ml}$ of fraction $\mathrm{C}$ were diluted with $0.15 \mathrm{M}$ sucrose and centrifuged at $100,000 \times g_{\mathrm{av}}$ for $30 \mathrm{~min}$ (in polyallomer tubes) producing pellets approximately 2 to $3 \mathrm{~mm}$ in diameter. After removal of the supernatant fluid, a fixative consisting of $2 \%$ glutaraldehyde and $2 \%$ osmium tetroxide in $0.05 \mathrm{M}$ phosphate buffer, $\mathrm{pH} 7.3$, was added in a slow stream down the side 
of the tube so as to fix the pellet in place. After $4 \mathrm{hr}$ at room temperature, the pellet was rinsed in buffer, dehydrated in graded ethanols through propylene oxide, and embedded in Epon. Blocks containing the pellets were mounted on epoxy chucks and trimmed for thin sectioning so that each thin section spanned the full gradient of the pellet. Electron micrographs were taken from the top (centripetal), middle, and bottom (centrifugal) levels of each sample. Sections were examined either unstained or stained with lead citrate and uranyl acetate.

Subce/lular marker enzymes. The activities of lactate dehydrogenase and fumarase were used as markers for cytosol and mitochondria, respectively. Assays were as described previously (Whittaker and Barker, 1972) with minor modifications. In addition, the activity of choline acetyltransferase was used as a marker for synaptosomes. Since, in the cerebral cortex, cholinergic neurons are mainly represented by terminal axons and presynaptic bulbs, choline acetyltransferase can be utilized as a specific synaptosomal rathe than general cytosolic marker (Whittaker and Barker, 1972). It was assayed by the liquid ion exchange method of Fonnum (1975).

Prior to assay, subcellular fractions were adjusted to a final concentration of $0.5 \%(\mathrm{v} / \mathrm{v})$ Triton $\mathrm{X}-100$ to ensure total release of enzyme activity.

Enzyme activities were proportional to the amount of protein used and to time of incubation.

Preparation of proteins. The smooth muscle phosphorylatable 20,000 dalton myosin light chain $\left(\mathrm{LC}_{20}\right)$ was prepared with minor modifications as previously described (Gallis et al., 1983). Skeletal muscle myosin light chains were prepared as previously described (Edelman and Krebs, 1982). Calmodulin from bovine brain or erthyrocytes was purified by DEAE and fluphenazineSepharose essentially according to the method of Kakiuchi et al., (1981). Calmodulin from these two sources was found to be equally effective in stimulating myosin light chain phosphorylating activity and was therefore used interchangeably.

Assay of myosin light chain phosphorylating activity. The assay procedure was modified from that used previously (Edelman and Krebs, 1982) Unless otherwise noted, myosin light chain phosphorylating activity was assayed in a solution containing $0.5 \mathrm{~mm}$ dithiothreitol, $0.5 \mathrm{mg} / \mathrm{ml}$ of bovine serum albumin, $1 \mathrm{~mm}$ ouabain, $12.5 \mathrm{~mm} \mathrm{MgCl}_{2}, 1 \mathrm{~mm}\left[\gamma^{32} \mathrm{P}\right]$ ATP $(0.06$ to $0.26 \mathrm{Ci} / \mathrm{mmol}$; New England Nuclear), $100 \mu \mathrm{M} \mathrm{LC}_{20}$, and traces of buffer components from the various protein storage buffers. The reactions were buffered with 50 mM PIPES (piperazine- $N$ - $N$ '-bis-2-ethanesulfonic acid), $\mathrm{pH}$ 6.6. As described under "Results," varying the $\mathrm{pH}$ and buffer ion of the assay medium did not appreciably affect the observed distribution of activity. The final salt concentration ( $\mathrm{NaCl}$ and/or $\mathrm{KCl}$ ) was $0.1 \mathrm{M}$. Subcellular fractions were adjusted to a concentration of $0.2 \%(\mathrm{~V} / \mathrm{V})$ Triton $X-100$ and vortexed to release sequestered enzyme. The final Triton $X-100$ concentration in the assay was 0.01 to $0.04 \%(\mathrm{v} / \mathrm{v})$. After incubation at $25^{\circ} \mathrm{C}$ for varying lengths of time, ${ }^{32} \mathrm{P}$ incorporation was determined by spotting an aliquot of the reaction mix onto a $2 \mathrm{~cm} \times ? \mathrm{~cm}$ square of $\mathrm{FT}$ cellulose paper and washing in trichloroacetic acid essentially as described previously (Edelman and Krebs, 1982)

Aternatively, ${ }^{32} \mathrm{P}$ incorporation was determined as follows. Reactions were quenched by heating at $95^{\circ} \mathrm{C}$ in the presence of $1 \%(\mathrm{~W} / \mathrm{V})$ sodium dodecyl sulfate (SDS) and $2 \%(\mathrm{~V} / \mathrm{v}) \beta$-mercaptoethanol for 4 min, following which the samples were subjected to SDS-polyacrylamide gel electrophoresis (Laem$\mathrm{mli}, 1970$ ). The band corresponding to $\mathrm{LC}_{20}$ was excised from the gel and combusted with $\mathrm{H}_{2} \mathrm{O}_{2}$ at $\sim 75^{\circ} \mathrm{C}$ overnight until dry. The residue was redissolved in $1.5 \%(\mathrm{w} / \mathrm{v})$ ascorbic acid and subjected to liquid scintillation spectrometry. Values were corrected for phosphorylation of any endogenous substrates running at $\sim 20,000$ daltons and $\mathrm{Ca}^{2+} /$ calmodulin-independent light chain phosphorylation as described below. Since values were within $10 \%$ of those obtained with the filter paper method, unless otherwise indicated, the filter paper method was routinely employed.

For each dilution of each subcellular fraction, activity was measured in the presence of $\mathrm{Ca}^{2+} /$ calmodulin (1.25 $\mathrm{mm}$ and $5 \mu \mathrm{M}$, respectively) and in its absence $\left(6 \mathrm{mM}\right.$ EGTA and calmodulin storage buffer substituted for $\mathrm{CaCl}_{2}$ and caimodulin, respectively). To each of these activities a correction for endogenous phosphorylation was applied by subtracting activities $\left( \pm \mathrm{Ca}^{2+}\right.$ and calmodulin) obtained in which light chain storage buffer was substituted for $\mathrm{LC}_{20}$. Subtraction of the corrected activity in the absence of $\mathrm{Ca}^{2+}$ / calmodulin from corrected activity in its presence expresses the final $\mathrm{Ca}^{2+}$ dependent, myosin light chain-dependent activity. As described under "Results" (Fig. 3), the Ca ${ }^{2+}$ dependence of this activity is conferred by calmodulin.

The $\mathrm{Ca}^{2+} /$ calmodulin-dependent myosin light chain phosphorylating activity in each subcellular fraction was linear with time and proportional to protein concentration under the conditions employed.

Both the specific activity and subcellular distribution of the myosin light chain phosphorylating activity were not appreciably affected by the inclusion of a phosphoprotein phosphatase inhibitor (50 mm inorganic phosphate) or by increasing by 2.5 -fold the ouabain concentration (results not presented), suggesting that the observed activity does not reflect the contribution of significant phosphoprotein phosphatase or $\mathrm{Na}^{+}, \mathrm{K}^{+}$-ATPase activities.

One unit of $\mathrm{Ca}^{2+} / \mathrm{calmodulin-dependent} \mathrm{myosin} \mathrm{light} \mathrm{chain} \mathrm{phosphorylating}$ activity is defined as $1 \mathrm{pmol}$ of ${ }^{32} \mathrm{P}$ incorporated in $1 \mathrm{~min}$ at $25^{\circ} \mathrm{C}$ in the above assay conditions.

Other methods. Protein was determined for both subcellular fractions and $\mathrm{LC}_{20}$ by the method of Lowry et al. (1951) utilizing some modifications suggested by Peterson (1977). Calmodulin concentrations were determined spectrophotometrically $\left(E_{280}^{0.1 \%}=0.21\right)$.

\section{Results}

Rat cerebral cortex was fractionated under iso-osmotic conditions as outlined in Figure 1 and the fractions were characterized by the distribution of subcellular marker enzymes (see Tables I to III) and by electron microscopy (Fig. 2).

To determine the correct substrate to use in assaying myosin light chain phosphorylating activity in brain subcellular fractions, two of the fractions were assayed with both smooth and skeletal muscle myosin light chains. In both a crude (initial homogenate) and highly purified fraction (density gradient fraction C) the activity observed was specific for the smooth as compared with the skeletal muscle phosphorylatable myosin light chain. The same result was obtained in extracts of rat brain prepared using either high or low saltcontaining buffers in the absence of sucrose with more vigorous homogenization (Waring blender) (results not shown). These results are consistent with brain being of a "smooth muscle type" system and, given the similarity in phosphorylation sites between smooth muscle and brain myosin light chain (Barylko and Sobieszek, 1983), we considered smooth muscle myosin light chain $\left(\mathrm{LC}_{20}\right)$ an appropriate substitute for the homologous brain myosin light chain (the latter being difficult to obtain in the large amounts needed for these studies).

Figure 3 illustrates the calcium and calmodulin dependence of myosin light chain phosphorylating activity in all of the subcellular fractions used in this study. Most of the activity $(\sim 50$ to $80 \%)$ in all fractions was dependent upon the combined presence of calcium and calmodulin. A smaller but significant amount of calcium-independent activity was also detected, confirming a report of calciumindependent light chain phosphorylation by kinase(s) from bovine brain (Matsumura et al., 1982). Subtraction of the latter activity from the $\mathrm{Ca}^{2+} /$ calmodulin-dependent activity thereby allowed exclusion of the contribution of calcium-independent activity (as well as possible $\mathrm{Ca}^{2+}$ /lipid-dependent activity since the calcium-alone activity did not differ significantly from the calcium-independent activity). The concentration of calmodulin added in the assay $(5 \mu \mathrm{M})$ produced maximal activation in all subcellular fractions (results not shown). The ability of added calmodulin to activate despite the fact that brain is reported to have a relatively high endogenous calmodulin content (Kakiuchi et al., 1982) is probably attributable to three factors: the extensive dilution of the fractions prior to assay, the presence of endogenous calmodulin-binding proteins in brain, and the likelihood (discussed further under "Discussion") that much, if not all, of the activity is attributable to the brain calmodulin-dependent kinase, an enzyme with a relatively poor affinity for calmodulin (Kennedy et al., 1983b).

Table I shows that in the primary subcellular fractions the $\mathrm{Ca}^{2+}$ / calmodulin-dependent light chain phosphorylating activity was highest in the synaptosome-enriched fraction ( $P_{2}$, crude mitochondria). The nuclear fraction contained a variable amount of activity, much of which was due to incompletely disrupted tissue as estimated by recovery of marker enzymes in this fraction. Low levels of activity were associated with the microsomal and cytosolic fractions, the latter also consistently having the lowest specific activity.

Juskevich et al. (1982) reported that calcium/calmodulin-dependent protein kinase activity was unstable at $4^{\circ} \mathrm{C}$ in brain cytosol, the instability being more severe in the presence of calcium. This was 


\section{Rat Cerebral Cortex}

homogenize in sol A (O.32M sucrose, $5 \mathrm{mM}$ Hepes $\mathrm{pH} 7.4)$

$10 \%(w / v)$ with wide clearonce leflon-glass homogenizer

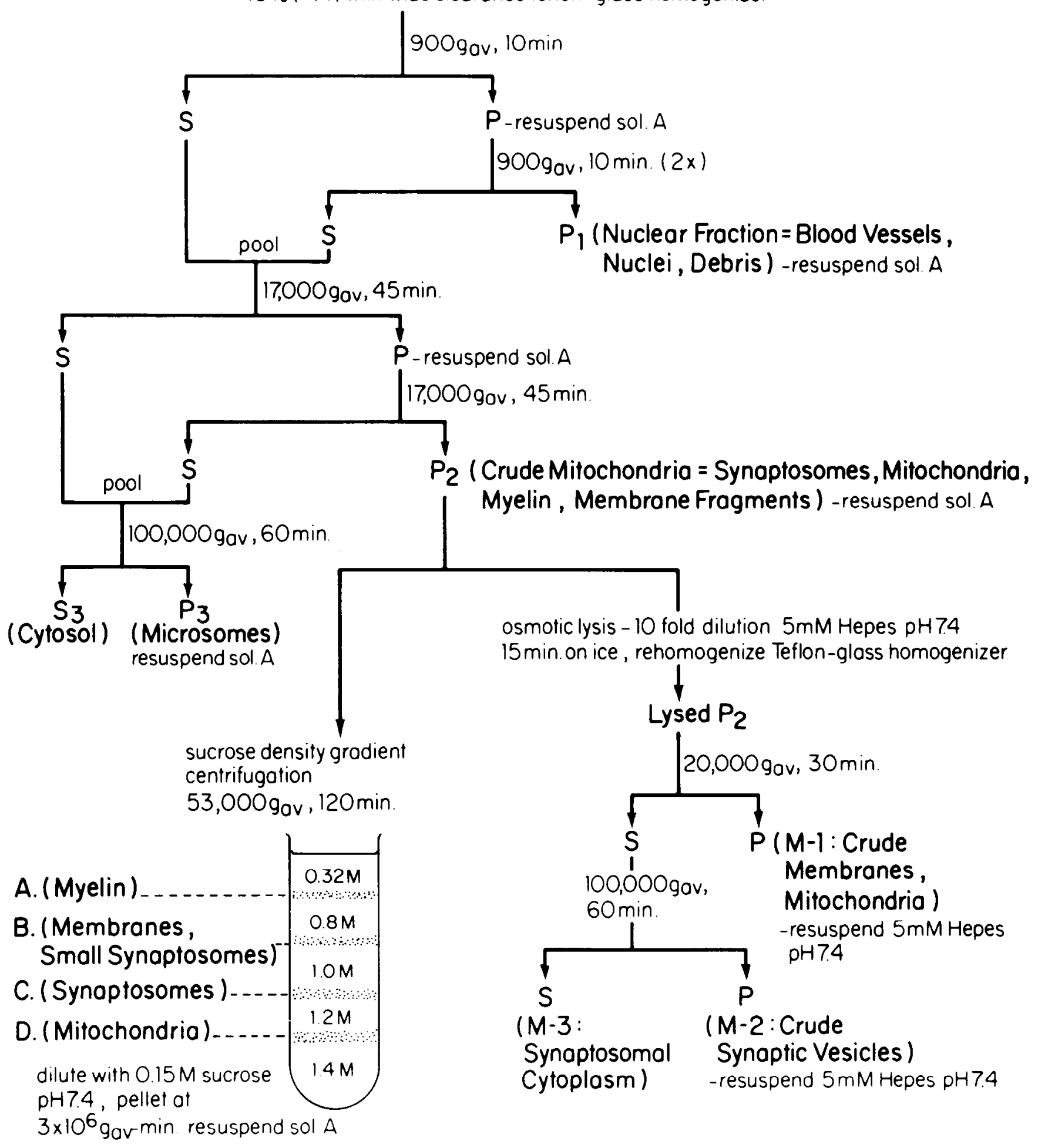

Figure 1. Scheme for subcellular fractionation of rat cerebral cortex.

due presumably to $\mathrm{Ca}^{2+}$-dependent proteolysis or a $\mathrm{Ca}^{2+}$-stimulated instability of the enzyme itself. We therefore investigated the possibility that the low recovery and low specific activity in the cytosolic fraction (Tables I and II) were due to such an instability phenomonon. We therefore performed a control experiment (results not shown) in which immediately after preparation of the fractions an aliquot of each fraction was stored at $4^{\circ} \mathrm{C}$ (for $\sim 1 \mathrm{hr}$ prior to assay) in either the usual media (0.32 $\mathrm{M}$ sucrose, $5 \mathrm{~mm}$ HEPES, $\mathrm{pH} 7.4$ ) or in a buffer containing $5 \mathrm{~mm}$ HEPES, $0.32 \mathrm{M}$ sucrose, $1 \mathrm{~mm}$ EDTA, $1 \mathrm{~mm}$ EGTA, $0.1 \mathrm{~mm}$ phenylmethylsulfonyl fluoride, $10 \mu \mathrm{M}$ leupeptin, $\mathrm{pH}$ 

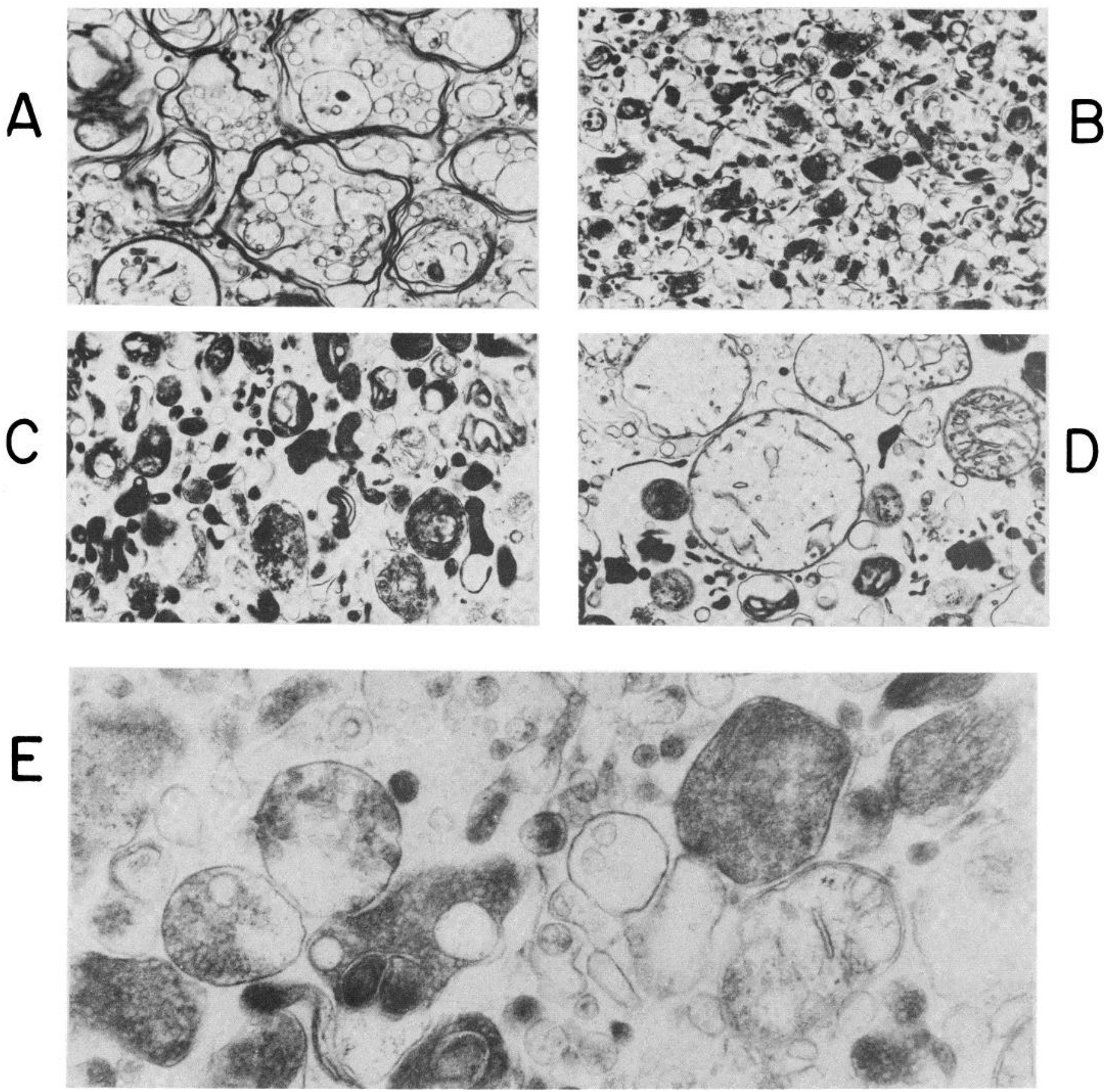

Figure 2. Electron micrographs of components of the crude mitochondrial fraction subfractionated by density gradient centrifugation. $A$ to $D$ represent density gradient fractions A to $D$, respectively. Pellets were prepared as described under "Materials and Methods." Micrographs represent the centrifugal level of each pellet. Sections were stained with lead citrate and uranyl acetate. Magnification $\times 12,500 E$ represents density gradient fraction $C$ at higher magnification $(\times 37,000)$. Unstained section.

7.4. Although the specific activities of all fractions were somewhat higher in this latter buffer, the percentage of activity recovered in cytosol was essentially the same in the latter buffer as in the former (14.3 versus $11.1 \%$, respectively), and again the specific activity in cytosol was lowest of all the fractions. Also, the linearity of enzyme activity upon dilution in all fractions suggests that dissociable inhibitors or activators are not a confounding factor in these measurements. These results argue for the likelihood that the low activity in the cytosol reflects a genuinely low abundance of enzyme in cytoplasm in this tissue.
The subcellular fractions were routinely assayed using $50 \mathrm{~mm}$ PIPES, pH 6.6. In a separate experiment (results not shown) fractions were assayed using 50 mM HEPES, pH 7.65, instead. Nearly identical results were obtained for the distribution of activity, although the higher $\mathrm{pH}$ gave a somewhat ( 2-fold) higher specific activity. From these results it was concluded that assay $\mathrm{pH}$ was not an important variable in these studies.

The crude mitochondrial fraction $\left(P_{2}\right)$, containing synaptosomes, free mitochondria, myelin, and membrane fragments, was further fractionated by discontinuous sucrose gradient ultracentrifugation 
Fractionation:

Primary

Subcellular

Fractions
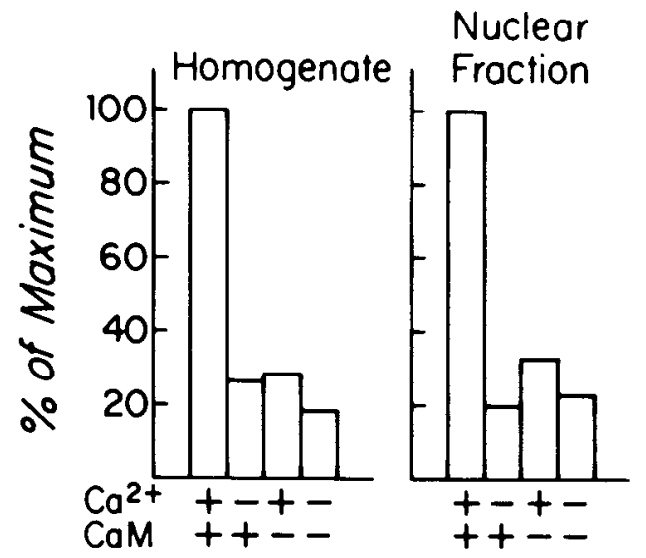

Crude
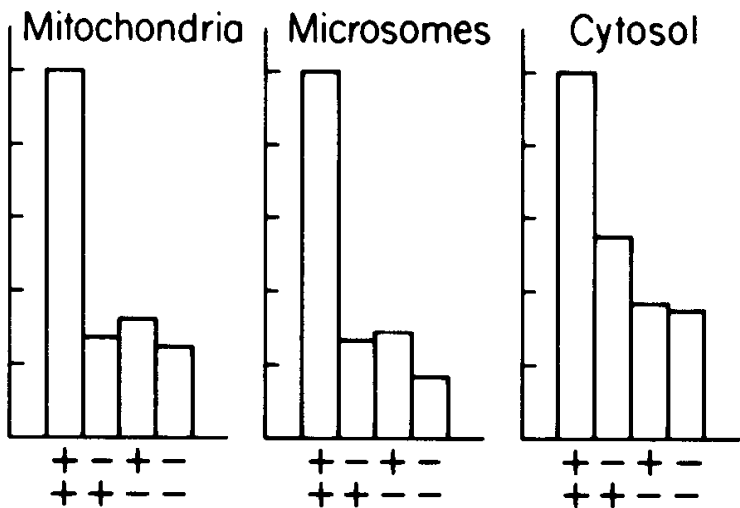

Submitochondrial

Fractions

Separated

By Sucrose

Density Gradient

Centrifugation
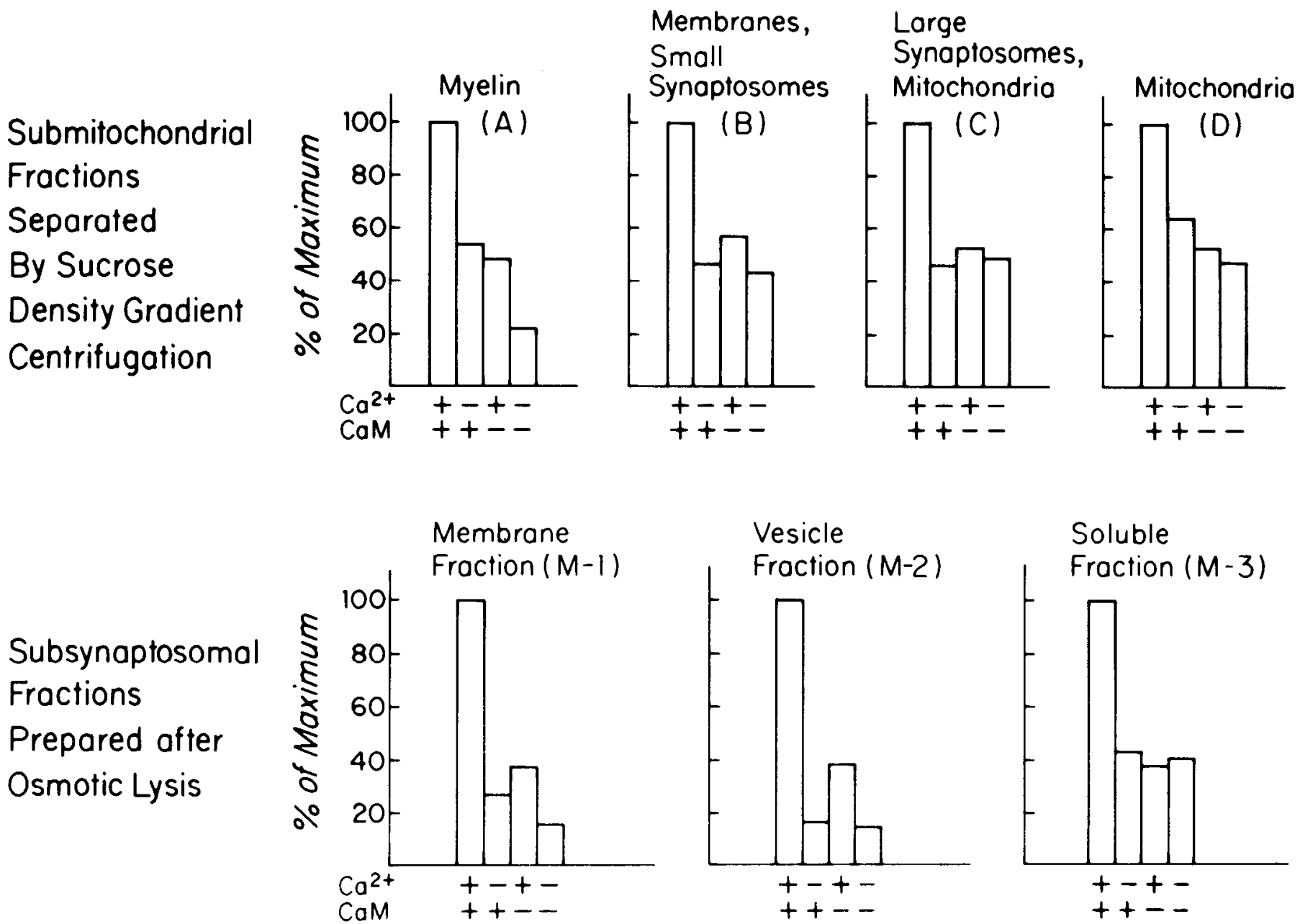

Figure 3. Calcium and calmodulin dependence of myosin light phosphorylating activity in subcellular fractions of rat cerebral cortex. Subcellular fractions were generated and myosin light chain phosphorylating activity was measured as described under "Materials and Methods." Activity was measured under the following conditions: $1.25 \mathrm{mM} \mathrm{CaCl}_{2}$ plus $5 \mu \mathrm{M}$ calmodulin $(+) ; 6 \mathrm{~mm}$ EGTA plus $5 \mu \mathrm{M}$ calmodulin $(\mp) ; 1.25 \mathrm{mM} \mathrm{CaCl}_{2}$ plus calmodulin storage buffer $( \pm)$; and $6 \mathrm{mM}$ EGTA plus calmodulin storage buffer $(=)$. Endogenous phosphorylation was separately measured under each experimental condition and subtracted. Activity is cxprossed as the percentage of the activity obtained in the presence of $\mathrm{Ca}^{2+}$ plus calmodulin in each subcellular fraction.

as illustrated in Figure 1. The fractions were characterized by electron microscopy (Fig. 2) and marker enzymes (Table I) as follows: A, myelin fragments and some small membrane fragments, B, small synaptosomes and membrane fragments, $C$, predominantly larger synaptosomes, and D, many free mitochondria, often swollen. Fraction $C$ was re-examined at higher magnification $(\times 37,500)$ without staining (Fig. 2E). Many synaptosomal profiles are in evidence with densely packed intraterminal synaptic vesicles. The dense packing probably explains why under lower magnification and with staining (Fig. 2, $B$ and $C$ ) synaptosomes appear darkened. The dense packing of vesicles and distortion in shape of some of the synaptosomes is characteristic of preparation under these conditions (cold hypertonic media) as was reported by Hajos and Csillag (1976).

Table I shows that the $\mathrm{Ca}^{2+} /$ calmodulin-dependent myosin light 
TABLE 1

Distribution of $\mathrm{Ca}^{2+} / \mathrm{calmodulin-dependent} \mathrm{myosin} \mathrm{light} \mathrm{chain} \mathrm{phosphorylating} \mathrm{activity} \mathrm{in} \mathrm{subcellular} \mathrm{fractions} \mathrm{of} \mathrm{rat} \mathrm{cerebral} \mathrm{cortex}{ }^{\mathrm{a}}$

\begin{tabular}{|c|c|c|c|c|c|c|c|}
\hline \multirow[b]{2}{*}{ Fraction } & \multirow{2}{*}{$\begin{array}{c}\text { Protein } \\
\text { (mg/gm of tissue) }\end{array}$} & \multicolumn{3}{|c|}{ Light Chain Phosphorylating Activity } & \multicolumn{3}{|c|}{$\mathrm{RSA}^{\mathrm{b}}$} \\
\hline & & $\begin{array}{c}\text { Total Activity } \\
\text { (units/mg of tissue) }\end{array}$ & $\begin{array}{c}\text { Specific Activity } \\
\text { (units/mg of protein) }\end{array}$ & $\begin{array}{c}\text { Distribution } \\
(\%)\end{array}$ & $\mathrm{CAT}^{\circ}$ & FUM & $\mathrm{LDH}$ \\
\hline \multicolumn{8}{|l|}{ Primary Fractions } \\
\hline Nuclear fraction $\left(P_{1}\right)$ & 12.5 & 53.9 & 4312 & 28.3 & 0.76 & 0.88 & 0.62 \\
\hline Crude mitochondria $\left(\mathrm{P}_{2}\right)$ & 28.5 & 109.7 & 3849 & 57.6 & 1.43 & 1.87 & 0.86 \\
\hline Microsomes $\left(\mathrm{P}_{3}\right)$ & 3.9 & 11.4 & 2923 & 6.0 & 0.78 & 0.64 & 0.83 \\
\hline Cytosol $\left(\mathrm{S}_{3}\right)$ & 13.9 & 15.3 & 1101 & 8.0 & 0.54 & 0 & 1.69 \\
\hline Total & 58.8 & 190.3 & & & & & \\
\hline $\begin{array}{l}\text { Starting material (homog- } \\
\text { enate) }\end{array}$ & 67.1 & 233.8 & 3484 & & & & \\
\hline Recovery $(\%)$ & 87.6 & 81.4 & & & & & \\
\hline \multicolumn{8}{|l|}{ Submitochondrial fractions } \\
\hline A. Myelin & 1.91 & 1.25 & 654 & 7.2 & 0.55 & 0.17 & 0.54 \\
\hline $\begin{array}{l}\text { B. Membranes, small } \\
\text { synaptosomes }\end{array}$ & 1.87 & 1.63 & 872 & 9.4 & 1.58 & 0.69 & 1.24 \\
\hline C. Synaptosomes & 8.4 & 13.27 & 1580 & 76.9 & 1.08 & 1.05 & 1.10 \\
\hline D. Free mitochondria & 2.05 & 1.11 & 541 & 6.4 & 0.42 & 2.24 & 0.71 \\
\hline Total & 14.23 & 17.26 & & & & & \\
\hline $\begin{array}{l}\text { Starting material (crude } \\
\text { mitochondria) }\end{array}$ & 26.2 & 83.4 & 3180 & & & & \\
\hline Recovery (\%) & 54.3 & 20.7 & & & & & \\
\hline
\end{tabular}

${ }^{2}$ Results represent the averages of three (submitochondrial fractions) or four (primary fractions) separate distributions.

${ }^{b}$ RSA (relative specific activity) = percentage of recovered activity/percentage of recovered protein.

${ }^{\circ} \mathrm{CAT}$, choline acetyltransferase; FUM, fumarase; $\mathrm{LDH}$, lactate dehydrogenase.

TABLE ॥

$\mathrm{Ca}^{2+} / \mathrm{calmodulin-dependent} \mathrm{myosin} \mathrm{light} \mathrm{chain} \mathrm{phosphorylating} \mathrm{activity} \mathrm{in} \mathrm{subsynaptosomal} \mathrm{fractions} \mathrm{prepared} \mathrm{after} \mathrm{osmotic} \mathrm{lysis}{ }^{2}$

\begin{tabular}{|c|c|c|c|c|c|c|}
\hline \multirow{2}{*}{ Fraction and U/trastructure } & \multirow{2}{*}{$\begin{array}{c}\text { Protein } \\
\text { (mg/gm of tissue) }\end{array}$} & \multicolumn{3}{|c|}{ Light Chain Phosphorylating Activity } & \multicolumn{2}{|c|}{$\begin{array}{c}\text { Relative Specific } \\
\text { Activity }\end{array}$} \\
\hline & & $\begin{array}{c}\text { Total Activity } \\
\text { (units/mg of tissue) }\end{array}$ & $\begin{array}{c}\text { Specific Activity } \\
\text { (units/mg of protein) }\end{array}$ & $\begin{array}{c}\text { Distribution } \\
(\%)\end{array}$ & Fumarase & $\mathrm{LDH}^{b}$ \\
\hline M-1 Membrane fraction & 10.7 & 25.4 & 2370 & 65.1 & 1.47 & 0.49 \\
\hline M-2 Vesicle fraction & 1.5 & 5.7 & 3800 & 14.6 & 0.63 & 1.05 \\
\hline M-3 Soluble fraction & 4.5 & 7.9 & 1760 & 20.3 & 0 & 2.21 \\
\hline Recovery $(\%)^{c}$ & 80.3 & 101.6 & & & & \\
\hline
\end{tabular}

a Results represent the averages of three subsynaptosomal distributions.

${ }^{b} \mathrm{LDH}$, lactate dehydrogenase.

${ }^{c}$ Recovery is expressed as percentage of starting material (crude mitochondria), calculated for two of the distributions.

chain phosphorylating activity was overwhelmingly localized to the large synaptosome-containing fraction (C) which had $77 \%$ of the recovered activity and roughly 2 to 3 times the specific activity of the other fractions. The remaining $23 \%$ of the recovered activity was about equally distributed between fractions $A, B$, and $D$.

In a separate experiment (not shown) the density gradient centrifugation was performed as usual with the exception that, in addition to removing the interfaces, the rest of each sucrose layer was also removed. The interfaces were then combined with the appropriate inter-interface sucrose layers producing "expanded" fractions A to $D$. This led to a doubling in the overall recovery of light chain phosphorylating activity ( $30 \%$ to $65 \%$ ); however, the conclusions regarding subcellular distribution were much the same as those derived from Table I. Fraction C ("expanded") contained $55 \%$ of the recovered activity (versus $62 \%$ when only the interface was sampled). The remaining activity was about equally distributed between the other fractions. These results suggest that the centrifugation was stopped before particles had completely banded and this would account for the low recovery $(21 \%)$ shown in Table I, but that centrifuging longer, although producing a higher recovery, would not change substantially the conclusions that may be drawn from Table I.

As illustrated in Figure 1, the synaptosomes may be lysed by hypo-osmotic conditions to analyze the distribution of activity in subsynaptosomal compartments. As shown in Table II, the activity was almost entirely particulate ( $\mathrm{M}-1$ plus $\mathrm{M}-2)$, although there was consistently about $20 \%$ recovered in the soluble fraction (M-3). Although $15 \%$ of the activity was recovered in $\mathrm{M}-2$ (the crude synaptic vesicle fraction), it cannot be concluded from these data alone that there is an association of the activity with synaptic vesicles since it is likely that $M-2$ contains a heterogeneity of small membrane fragments in addition to synaptic vesicles.

Fonnum (1967) demonstrated that after hypo-osmotic lysis of synaptosomes, the synaptosomal enzyme, choline acetyltransferase, is almost entirely particulate but becomes nearly completely soluble by treatment of the lysate with $75 \mathrm{~mm} \mathrm{NaCl}$. This suggested to us that, by analogy, the myosin light chain phosphorylating activity might be artifactually bound to membranes simply as a consequence of the low ionic strength during the hypo-osmotic lysis. We therefore treated the $\mathrm{M}-1$ fraction with $5 \mathrm{~mm}$ HEPES, $\mathrm{pH} 7.4$, plus $75 \mathrm{mM} \mathrm{NaCl}$. 
The result shown in Table III was that the activity was not released from membranes by this treatment. Kennedy et al. (1983b) reported that brain calmodulin-dependent kinase could be desorbed from membranes by dilution into a low ionic strength buffer. However, 9 fold dilution of the membrane fraction into $5 \mathrm{~mm}$ HEPES, $\mathrm{pH} 7.4$, without salt, did not desorb the light chain phosphorylating activity (Table lil). In addition, since the $\mathrm{M}-1$ fraction was stored at $-70^{\circ} \mathrm{C}$ prior to these experiments, freeze-thawing is part of the treatment. As seen in Table III, it is also ineffective in releasing the activity.

There have been a number of reports that the membrane association of specific proteins is calcium dependent (Obrink et al., 1976; Walker, 1982). In this case, one might envision such an association mediated by the calcium-binding protein, calmodulin. Chelator treatment (4 mM CDTA) did not, however, release the light chain phosphorylating activity from membranes (Table III).

Data from Table III suggest that most of the $\mathrm{Ca}^{2+} / \mathrm{calmodulin}$ dependent light chain phosphorylating activity is genuinely membrane associated, although the strength of this association and whether the association is directly with the plasma membrane or indirectly through cytoskeletal elements remains to be evaluated.

\section{Discussion}

On the basis of several considerations, it appears likely that much, if not all, of the $\mathrm{Ca}^{2+}$ /calmodulin-dependent activity measured in this study is attributable to brain calmodulin-dependent kinase with myosin light chain kinase making up a relatively smaller percentage of the total. In a separate experiment (not shown), the $\mathrm{Ca}^{2+}$-dependent myosin light chain phosphorylating activity in synaptosomal membranes $(\mathrm{M}-1)$ was measured as a function of calmodulin concentration. The apparent activation constant $\left(K_{\text {act }}\right)$ was $259 \mathrm{~nm}$. Although precise determination of this kinetic constant may be difficult for such a crude system, the activation constant that was obtained is most similar to those reported for purified preparations of the brain calmodulin-dependent kinase ("average" value: $100 \mathrm{~nm}$; range: 10 to $400 \mathrm{~nm}$; Fukunaga et al., 1982; Goldenring et al., 1983; Kennedy et al., 1983b; Yamauchi and Fujisawa, 1983; Schulman, 1984). This is clearly distinguished from myosin light chain kinase, which has an activation constant for calmodulin of $1 \mathrm{nM}$ (Adelstein et al., 1982). Furthermore, when the membranes werc proincubated with added MgATP and purified catalytic subunit of cyclic AMPdependent protein kinase, only a minor change was found in the $K_{\text {act }}(386 \mathrm{~nm})$, again suggesting the involvement of brain calmodulindependent kinase since, by contrast, myosin light chain kinase has

TABLE H

Membrane association of $\mathrm{Ca}^{2+} / \mathrm{calmodulin-dependent} \mathrm{myosin} \mathrm{light} \mathrm{chain}$ phosphorylating activity

The preparation of fractions was as follows (all procedures at 0 to $4^{\circ} \mathrm{C}$ ). Crude membranes $\left(\mathrm{M}-1\right.$, stored at $\left.-70^{\circ} \mathrm{C}\right)$ were diluted 9-fold with either 5 mM HEPES, pH 7.4 (control), 5 mM HEPES (pH 7.4) plus $75 \mathrm{~mm}$ (final) $\mathrm{NaCl}$ ( $\mathrm{NaCl}$-treated), or $5 \mathrm{~mm}$ HEPES (pH 7.4), $4 \mathrm{~mm}$ EDTA (EDTA-treated). Fractions were then vigorously vortexed and remained on ice for 30 min after which they were centrifuged in polyallomer tubes at $100,000 \times g_{a v}$ for 30 min. Supernatants and pellets were analyzed for $\mathrm{Ca}^{2+} / \mathrm{calmodulin}$-dependent myosin light chain phosphorylating activity after dilution into $0.2 \%$ Triton $X$ 100 as described under "Materials and Methods."

$$
\text { Percentage distribution }=\frac{\text { activity recovered in each fraction }}{\text { total activity recovered }} \times 100
$$

The recoveries from starting material (M-1) were $96 \%$ for control, and $69 \%$ and $121 \%$ for $\mathrm{NaCl}$-treated and EDTA-treated membranes, respectively. Results represent the average of two to four separate preparations for each condition

\begin{tabular}{lccc}
\hline & \multicolumn{3}{c}{ Treatment (Percentage Distribution) } \\
\cline { 2 - 4 } & Control & NaCl-treated & EDTA-treated \\
\hline Supernatant & 4.7 & 4.8 & 3.5 \\
Pellet & 95.3 & 95.2 & 96.5 \\
\hline
\end{tabular}

been reported to undergo a large change (15-fold decrease) in its affinity for calmodulin upon phosphorylation by cyclic AMP-dependent protein kinase (Adelstein et al., 1982). Finally, a third piece of evidence comes from another experiment (not shown) in which we assayed for $\mathrm{Ca}^{2+}$-dependent phosphorylating activity in the $\mathrm{P}_{2}$ fraction using either synapsin I, a synaptic vesicle-associated protein which is also a substrate for brain calmodulin-dependent kinase (Bennett et al., 1983; McGuinness et al., 1983), or smooth muscle myosin light chain at saturating concentrations (7 $\mu \mathrm{M}$ and $100 \mu \mathrm{M}$, respectively). ${ }^{3}$ The activity toward synapsin I was roughly 1.5 times that toward myosin light chain, a value very close to that reported by Bennett et al. (1983) (correcting for differing substrate concentrations) for pure calmodulin-dependent kinase. The quantitative similarity in substrate specificity between the $P_{2}$ fraction and purified calmodulin-dependent kinase again suggests a relative lack of involvement of myosin light chain kinase since a contribution from the latter enzyme would be expected to result in a much lower synapsin l/light chain activity ratio. Although the above considerations point to brain calmodulin dependent kinase as the primary activity being measured in this study, they clearly do not preclude some contribution from myosin light chain kinase. It should be re-emphasized, however, that since both myosin light chain kinase and brain calmodulin-dependent kinase stimulate actin-activated myosin ATPase activity (Barylko and Sobieszek, 1983; A. M. Edelman, M. B. Ken nedy, and E. G. Krebs, manuscript in preparation), the implications for myosin regulation of the distribution studies presented here are not critically dependent on the precise relative contribution of each enzyme.

A number of studies, utilizing differing methodologies, have been done to date on the question of the subcellular localization of brain calmodulin-dependent kinase. This enzyme was originally identified as a component of the membrane fraction of mammalian brain (Schulman and Greengard, 1978). It has now been purified from both particulate (Kennedy et al., 1983b; Fukunaga et al., 1984; Sahyoun et al., 1985) and cytosolic (Fukunaga et al., 1982; Bennett et al., 1983; Goldenring et al., 1983; Yamauchi and Fujisawa, 1983, Kuret and Schulman, 1984) brain fractions. The initial step in these purifications typically involves homogenization in a low ionic strength buffer, a treatment which has been reported to yield $\sim 30$ to $45 \%$ of the activity in the high speed supernatant (Kennedy and Greengard, 1981). Of the activity recovered in the pellet, another 50 to $70 \%$ was reported to be solubilized by dilution into a low ionic strength buffer (Kennedy et al., 1983b).

Subcellular fractionation studies, which tend to employ mild conditions such as the use of iso-osmotic buffers, have found a relatively low percentage of the activity in cytosolic fractions. Yamauchi and Fujisawa (1981) and Landt et al. (1982) found that roughly $43 \%$ and $3 \%$, respectively, of the calmodulin-dependent kinase activity was in the cytosolic fraction. We report here that only $\sim 20 \%$ of the $\mathrm{Ca}^{2+}$ / calmodulin-dependent light chain phosphorylating activity in rat cerebral cortex is cytosolic $\left(S_{3}+M_{3} \times P_{2}\right)$ and that the activity in the membrane fraction (M-1) could not be desorbed by freeze thawing, $75 \mathrm{~mm} \mathrm{NaCl}$, EDTA treatment, or dilution into a low ionic strength buffer.

The presence of calmodulin-dependent kinase has also been demonstrated in a variety of isolated neuronal subcellular structures. Grab et al. (1981) demonstrated that isolated postsynaptic densities contain calmodulin-dependent kinase activity. Subsequently, the major postsynaptic density protein (mPSDp) was identified as a subunit of the brain calmodulin-dependent kinase (Kennedy et al., 1983a; Goldenring et al., 1984; Kelly et al., 1984). The mPSDp was found to be present in relatively low concentrations in cytosol as compared with synaptic junctional preparations, and neither the

\footnotetext{
${ }^{3} K_{\mathrm{m}}$ values of brain calmodulin-dependent kinase are taken as: $30 \mu \mathrm{M}$ for smooth muscle myosin light chain (Fukunaga et al., 1982) and $0.4 \mu \mathrm{M}$ for synapsin I (Kennedy et al., 1983b).
} 
mPSDp nor observable calmodulin stimulated kinase activity could be released from synaptic junctions by various extraction procedures (including dilution into low ionic strength buffer) (Kelly et al., 1984). Similarly, Sahyoun et al. (1985) reported that brain calmodulindependent kinase was present in a detergent-insoluble cytoskeletal residue from which it could not be extracted by detergents, salts, divalent ion chelators, or low ionic strength buffers. Also, both isolated neuronal nuclei (Sahyoun et al., 1984a, b) and an enriched synaptic vesicle preparation (Burke and DeLorenzo, 1982) have been shown to contain the calmodulin-dependent kinase. Finally, Ouimet et al. (1984) studied the localization in brain of the calmodulindependent kinase by immunocytochemistry. Immunoreactivity was observed in the cytoplasm, on the plasmalemma, on mitochondria, and on synaptic vesicles and microtubules, as well as on postsynaptic densities. Thus, to summarize the current state of knowledge concerning the subcellular localization of the calmodulin-dependent kinase, it would appear that a significant portion of the enzyme is firmly bound to membranes or cytoskeletal elements with the remainder present in the cytosol and loosely bound to membranes, with the relative percentage recovered in the cytosol perhaps dependent on the specific conditions of homogenization employed.

We find most of the myosin light chain phosphorylating activity associated with nerve endings. Two other prominent protein kinase activities in brain, cyclic AMP-dependent protein kinase, and $\mathrm{Ca}^{2+}$ and lipid-dependent protein kinase, are distributed somewhat more broadly than is the light chain phosphorylating activity studied here (Maeno et al., 1971; Walter et al., 1978; Kikkawa et al., 1982). In primary subcellular fractions 35 to $45 \%$ of the former two kinase activities were lound in cytosol, significantly higher than we report here for the light chain phosphorylating activity $(\sim 10 \%)$, and, in the case of cyclic AMP-dependent protein kinase, there is also significant activity associated with microsomes. Thus, it may be that, reflecting its more restricted localization, the kinase activity studied here is more specialized in its function, perhaps having a role in the physiology of the neuronal cytoskeleton. In this context, it is to be noted that some of the best substrates for the brain calmodulin-dependent kinase, namely, synapsin-I, microtubule-associated protein, tubulin, myosin light chain, and myelin basic protein, are associated with membranes and/or the neuronal cytoskeleton (Fukunaga et al., 1982; Bennett et al., 1983; Goldenring et al., 1983; McGuinness et al., 1983; Schulman, 1984). It is also of interest that the three major classes of brain protein kinases described to date, the cyclic AMP, $\mathrm{Ca}^{2+} /$ calmodulin-, and $\mathrm{Ca}^{2+} /$ lipid-dependent kinases, all are present in significant amounts in nerve endings and are largely membrane associated within the nerve ending. This speaks to the general possibility that the events related to the process of synaptic transmission may in some way regulate or be regulated by protein phosphorylation-dephosphorylation.

Actin, myosin, and calmodulin are all present in synaptic areas (Toh et al., 1976; Grab et al., 1979; Lin et al., 1980; Wood et al., 1980; Beach et al., 1981; Matus et al., 1982; Drenckhahn and Kaiser, 1983). As we have shown in this report, calmodulin-dependent myosin phosphorylating activity is present in synaptosomes and associated with synaptosomal membranes. Thus, it appears that all of the elements for a calcium-dependent actomyosin system exist in the region of the synapse. Such a system could function to effect dendritic spine shape changes consequent to stimulation (Cotman and Kelly, 1980), to control postsynaptic receptor mobility analogous to control of receptor capping in lymphoma cells by calcium-dependent myosin phosphorylation (Kerrick and Bourguignon, 1984), or be the mechanism by which neurotransmitter-containing vesicles move to the synapse during calcium-dependent neurotransmission, a hypothesis initially proposed some years ago by Berl et al. (1973). The possible participation of contractile proteins in such synaptic processes has been reviewed in detail elsewhere (Trifaro, 1978; Cotman and Kelly, 1980).

Note added in proof. After submission of this manuscript, a report appeared (Kelly, P. T., and P. Vernon (1985) Dev. Brain Res. 18:
211-224) which also documented the high proportion of calmodulin dependent kinase in particulate relative to cytosolic subcellular fractions of adult rat brain.

\section{References}

Adelstein, R. S. (1983) Regulation of contractile proteins by phosphorylation. J. Clin. Invest. 72: 1863-1866

Adelstein, R. S., J. R. Sellers, M. A. Conti, M. D. Pato, and P. deLanerolle (1982) Regulation of smooth muscle contractile proteins by calmodulin and cyclic AMP. Fed. Proc. 41: 2873-2878.

Anthony, F. A., J. A. Babitch, and S. K. Sharma (1984) Troponin is unlikely to occur in bovine and chick forebrain. J. Neurochem. 42: 1343-1349.

Barylko, B., and A. Sobieszek (1983) Phosphorylation and actin activation of brain myosin. EMBO J. 2: 369-374.

Beach, R. L., P. T. Kelly, J. A. Babitch, and C. W. Cotman (1981) Identification of myosin in isolated synaptic junctions. Brain Res. 225: 75-93.

Bennett, M. K., N. E. Erondu, and M. B. Kennedy (1983) Purification and characterization of a calmodulin-dependent protein kinase that is highly concentrated in brain. J. Biol. Chem. 258: 12735-12744.

Berl, S., S. Puszkin, and W. J. Nicklas (1973) Actomyosin-like protein in brain. Science 179: 441-446.

Blitz, A. L., and R. E. Fine (1974) Muscle-like contractile proteins and tubulin in synaptosomes. Proc. Natl. Acad. Sci. U. S. A. 71: 4472-4476.

Burke, B. E., and R. J. DeLorenzo (1982) $\mathrm{Ca}^{2+}$ and calmodulin-dependent phosphorylation of endogenous synaptic vesicle tubulin by a vesiclebound calmodulin kinase system. J. Neurochem. 38: 1205-1218.

Cotman, C. W. and P. T. Kelly (1980) Macromolecular architecture of CNS synapses. In The Cell Surface and Neuronal Function, C. W. Cotman, G. Poste, and G. L. Nicholson, eds., pp. 505-533, Elsevier-North Holland Publishing Co., Amsterdam.

Dabrowska, R., and D. J. Hartshorne (1978) A Ca ${ }^{2+}$ - and modulator-dependent myosin light chain kinase from non-muscle cells. Biochem. Biophys. Res. Commun. 85: 1352-1359.

DeRobertis, E., A. Pellcgrino de Iraldi, G. Rodriguez de Lores Arnaiz, and L. Salganicoff (1962) Cholinergic and non-cholinergic nerve endings in rat brain. I. Isolation and subcellular distribution of acetylcholine and acetyl. cholinesterase. J. Neurocherr. 9: 23-35.

DeRobertis, E., M. Alberici, G. Rodriguez de Lores Arnaiz, and J. M. Azcurra (1966) Isolation of different types of synaptic membranes from the brain cortex. Life Sci. 5: 577-582.

Drenckhahn, D., and H. W. Kaiser (1983) Evidence for the concentration of F-actin and myosin in synapses and in the plasmalemmal zone of axons. Eur. J. Cell Biol. 31: 235-240.

Edelman, A. M., and E. G. Krebs (1982) Phosphorylation of skeletal muscle myosin light chain kinase by the catalytic subunit of cAMP-dependent protein kinase. FEBS Lett. 138: 293-298.

Edelman, A. M., D. D. Hunter, A. E. Hendrickson, and E. G. Krebs (1984) $\mathrm{Ca}^{2+} /$ calmodulin-dependent myosin light chain phosphorylating activity: Nerve ending localization in rat cerebral cortex. J. Cell. Biochem. Suppl. 8B: $111 \mathrm{a}$

Fonnum, F. (1967) The "compartmentation" of choline acctyltransferase within the synaptosome. Biochem. J. 103: 262-270.

Fonnum, F. (1975) A rapid radiochemical method for the determination of choline acetyltransferase. J. Neurochern. 24: 407-409.

Fukunaga, K., H. Yamamoto, K. Matsui, K. Higashi, and E. Miyamoto (1982) Purification and characterization of a $\mathrm{Ca}^{2+}$. and calmodulin-dependent protein kinase from rat brain. J. Neurochem. 39: 1607-1617.

Fukunaga, K., H. Yamamoto, E. Tanaka, and E. Miyamoto (1984) A Ca ${ }^{2+}$ calmodulin-dependent protein kinase in the particulate fraction of rat brain and endogenous phosphorylation of particulate-bound substrates. Biomed. Res. 5: 165-176.

Gallis, B., A. M. Edelman, J. E. Casnellie, and E. G. Krebs (1983) Epidermal growth factor stimulates tyrosine phosphorylation of the myosin regulatory light chain from smooth muscle. J. Biol. Chem. 258: 13089-13093.

Goldenring, J. R., B. Gonzalez, J. S. McGuire, and R. J. DeLorenzo (1983) Purification and characterization of a calmodulin-dependent kinase from rat brain cytosol able to phosphorylate tubulin and microtubule associated proteins. J. Biol. Chem. 258. 12632-12640.

Goldenring, J. R., J. S. McGuire, Jr., and R. J. DeLorenzo (1984) Identification of the major postsynaptic density protein as homologous with the major calmodulin-binding subunit of a calmodulin-dependent protein kinase. J. Neurochem. 42: 1077-1084.

Grab, D. J., K. Berzins, R. S. Cohen, and P. Siekevitz (1979) Presence of calmodulin in postsynaptic densities isolated from canine cerebral cortex. J. Biol. Chem. 254: 8690-8696. 
Grab, D. J., R. K. Carlin, and P. Siekevitz (1981) Function of calmodulin in postsynaptic densities. 11. Presence of a calmodulin-activatable protein kinase activity. J. Cell Biol. 89: 440-448.

Hajos, F., and A. Csillag (1976) Structural changes in vitro of isolated nerve endings. I. Effect of cations. Brain Res. 112: 207-213.

Hathaway, D. R., R. S. Adelstein, and C. B. Klee (1981) Interaction of calmodulin with myosin light chain kinase and cAMP-dependent protein kinase in bovine brain. J. Biol. Chem. 256: 8183-8189.

Juskevich, J. C., D. M. Kuhn, and W. Lovenberg (1982) Calcium enhanced inactivation of calmodulin-dependent protein kinase from synaptosomes. Biochem. Biophys. Res. Commun. 108: 24-30.

Kakiuchi, S., K. Sobue, R. Yamazaki, J. Kambayashi, M. Sakon, and G. Kosaki (1981) Lack of tissue specificity of calmodulin: A rapid and highyield purification method. FEBS Lett. 126: 203-207

Kakiuchi, S., S. Yasuda, R. Yamazaki, Y. Teshima, K. Kanda, R. Kakiuchi, and K. Sobue (1982) Quantitative determinations of calmodulin in the supernatant and particulate fractions of mammalian tissues. J. Biochem. 92: $1041-1048$

Kelly, P. T., T. L. McGuinness, and P. Greengard (1984) Evidence that the major postsynaptic density protein is a component of a $\mathrm{Ca}^{2+} / \mathrm{calmodulin}$ dependent protein kinasc. Proc. Natl. Acad. Sci. U. S. A. 81: 945-949.

Kennedy, M. B., and P. Greengard (1981) Two calcium/calmodulin-dependent protein kinases which are highly concentrated in brain, phosphorylate prolein I at distinct sites. Proc. Natl. Acad. Sci. U. S. A. 78: 12931297.

Kennedy, M. B., M. K. Bennett, and N. E. Erondu (1983a) Biochemical and immunochemical evidence that the "major postsynaptic density protein" is a subunit of a calmodulin-dependent protein kinase. Proc. Natl. Acad. Sci. U. S. A. 80: 7357-7361

Kennedy, M. B., T. McGuinness, and P. Greengard (1983b) A calcium/ calmodulin-dependent protein kinase activity from mammalian brain that phosphorylates synapsin I: Partial purification and characterization. J. Neurosci. 3: 818-831.

Kerrick, W. G. L., and L. Y. W. Bourguignon (1984) Regulation of receptor capping in mousc lymphoma $T$ cells by $\mathrm{Ca}^{2+}$-activated myosin light chain kinase. Proc. Natl. Acad. Sci. U. S. A. 81: 165-169.

Kikkawa, U., Y. Takai, R. Minakuchi, S. Inohara, and Y. Nishizuka (1982) Calcium-dclivated, phospholipid-dependent protein kinase from rat brain. Subcellular distribution, purification and properties. J. Biol. Chem. 257: $13341-13348$.

Kuret, J., and H. Schulman (1984) Purification and characterization of $\mathrm{a} \mathrm{Ca}^{2+} /$ calmodulin-dependent protein kinase from rat brain. Biochemistry 23 : 5495-5504.

Laemmli, U. K. (1970) Cleavage of structural proteins during the assembly of the head of bacteriophage T4. Nature 227: 680-685.

Landt, M., R. F. Kloepper, B. E. Miller, C. L. Brooks, and J. M. McDonald (1982) A survey of calmodulin-activated protein kinase activity in several tissues of Rattus rattus. Comp. Biochem. Physiol. 73B: 509-516.

Lasek, R. J., and P. N. Hoffman (1976) The axonal transport of cytoskeletal proteins. In Cell Motility, R. Goldman, R. Pollard, and J. Rosenbaum, eds., pp. 1021-1049, Cold Spring Harbor Laboratory, Cold Spring Harbor, NY.

Letourneau, P. C. (1981) Immunocytochemical eviderice for co-localization in neurite growth cones of actin and myosin and their relationship to cell substratum adhesions. Dev. Biol. 85: 113-122.

Lin, C. -T., J. R. Dedman, B. R. Brinkley, and A. R. Means (1980) Localization of calmodulin in rat cerebellum by immunoelectron microscopy. J. Cell Biol. 85: 473-480.

Lowry, O. H., N. J. Rosebrough, A. L. Farr, and R. J. Randall (1951) Protein measurement with the Folin phenol reagent. J. Biol. Chem. 193: 265-275.

Maeno, H., E. M. Johnson, and P. Greengard (1971) Subcellular distribution of adenosine $3^{\prime}, 5^{\prime}$-monophosphate-dependent protein kinase in rat brain. J. Biol. Chem. 246: 134-142.

Matsumura, S., N. Murakami, S. Yasuda, and A. Kumon (1982) Site specific phosphorylation of brain myosin light chains by calcium-dependent and calcium-independent myosin kinases. Biochem. Biophys. Res. Commun. 109: $683-688$.

Matus, A., M. Ackermann, G. Pehling, H. R. Byers, and K. Fujiwara (1982) High actin concentrations in brain dendritic spines and postsynaptic densities. Proc. Natl. Acad. Sci. U. S. A. 79: 7590-7594.

McGuinness, T. L., Y. Lai, P. Greengard, J. R. Woodgelt, and P. Cohen (1983) Similarities between skeletal muscle glycogen synthase kinase and a brain synapsin I kinase. FEBS Lett. 163: 329-334

Obrink, B., H. Lindstrom, and N.- G. Svennung (1976) Calcium requirement for a reversible binding of membrane proteins to rat liver plasma membranes. FEBS Lett. 70: 28-32.

Peterson, G. L. (1977) A simplification of the protein assay of Lowry et al. which is more generally applicable. Anal. Biochem. 83: 346-356.

Puszkin, S., W. J. Nicklas, and S. Berl (1972) Actomyosin-like protein in brain: Subcellular distribution. J. Neurochem. 19: 1319-1333.

Sahyoun, N., H. LeVine H, D. Bronson, and P. Cuatrecasas (1984a) Ca ${ }^{2+}$ calmodulin-dependent protein kinase in neuronal nuclei. J. Biol. Chem. 259: 9341-9344

Sahyoun, N., H. LeVine III, and P. Cuatrecasas (1984b) $\mathrm{Ca}^{2+} /$ calmodulindependent protein kinases from the neuronal nuclear rratrix and postsynaptic density are structurally related. Proc. Natl. Acad. Sci. U. S. A. 81 : $4311-4315$

Sahyoun, N., H. LeVine III, D. Bronson, F. Siegel-Greenstein, and P. Cuatrecasas (1985) Cytoskeletal calmodulin-dependent protein kinase characterization, solubilization and purification from rat brain. J. Biol. Chem. 260: $1230-1237$

Schulman, H. (1984) Phosphorylation of microtubule-associated proteins by a $\mathrm{Ca}^{2+} /$ calmodulin-dependent protein kinase. J. Cell Biol. 99: 11-19.

Schulman, H., and P. Greengard (1978) Stimulation of brain membrane protein phosphorylation by calcium and an endogenous heat-stable protein. Nature 271: 478-479.

Toh, B. H., H. A. Gallichio, P. L. Jeffrey, B. G. Livett, H. K. Muller, M. N. Cauchi, and F. M. Clarke (1976) Anti-actin stains synapses. Nature 264. 648-650.

Trifaro, J. M. (1978) Contractile proteins in tissues originating in the neural crest. Neuroscience $3: 1-24$.

Walker, J. H. (1982) Isolation from cholinergic synapses of a protein that binds to membranes in a calcium-dependent manner. J. Neurochem. 39: 815-823.

Walter, U., P. Kanof, H. Schulman, and P. Greengard (1978) Adenosine $3^{\prime}: 5^{\prime}$-monophosphate receptor proteins in mammalian brain. J. Biol. Chem 253: $6275-6280$.

Whittaker, V. P., and L. A. Barker (1972) Subcellular fractionation of brain tissue with special reference to the preparation of synaptosomes and their component organelles. In Methods of Neurochemistry, R. Fried, ed., pp. 1-52, Marcel Dekker, New York.

Wood, J. G., R. W. Wallace, J. N. Whitaker, and W. Y. Cheung (1980) Immunocytochemical localization of calmodulin and a heat-labile calmod ulin-binding protein (CaM-BP ${ }_{80}$ ) in basal ganglia of mouse brain. J. Cell Biol. 84: 66-76

Yamauchi, T., and $\mathrm{H}$. Fujisawa (1981) A calmodulin-dependent protein kinase that is involved in the activation of tryptophan 5-monooxygenase is specifically distributed in brain tissues. FEBS Lett. 129: 117-119.

Yamauchi, T., and H. Fujisawa (1982) Phosphorylation of microtubule-associated protein 2 by calmodulin-dependent protein kinase (kinase II) which occurs only in the brain tissues. Biochem. Biophys. Res. Commun. 109. 975-981.

Yamauchi, T., and H. Fujisawa (1983) Purification and characterization of the brain calmodulin-dependent protein kinase (kinase II) which is involved in the activation of tryptophan 5-monooxygenase. Eur. J. Biochem. 132: 1521. 